The stimulation of growth and the savings in feed that are the possible results of fortifying a ration with antibiotics were also discussed. The picture continues to be indistinct. Where a condition exists for an antibiotic to exert a therapeutic effect, a spectacular result will be observed. In carefully controlled experinents small advantages will usually be found. In practical trials on farms the response to antibiotics is extremcly variable, but farmers may choose to pay for the safeguard that an antibiotic can give.

The conference concluded with a discussion of the role of the agricultural adviser who links the research worker and the practical farmer. There was frank recognition of difficulties that must continue to face those whos task it is to translate the new findings of research stations into profitable practices on the farms in Britain, where the farming systems are so diversified.

JOHN DUCKWORTH

\section{MIXING OF THICK LIQUIDS, PASTES AND SLURRIES}

$\mathrm{N}$ a recent report of the Committee on Chemical Engineering Research of the Department of Scientific and Industrial Research, it was pointed out that the general subject of mixing is one which would profit by more fundamental research. Although the mixing of thick materials is a matter of considerable industrial importance, there is virtually no basic information about such mixing problems, and most mixing machines have been designed by intuition and the use of empirical methods. On September 25 the British Society of Rheology organized in London a symposium on the "Mixing of Thick Liquids, Pastes and Slurries", in the hope of collecting what information is available and of clarifying the more important scientific aspects of the subject.

The symposium was opened by Mr. P. V. Danckwerts (Department of Chemical Engineering, University of Cambridge) with a paper on "General Aspects of Mixtures and Mixing". This excellent introduction to the subject first considered how the extent of mixing could be measured quantitatively. For this purpose Mr. Danckwerts introduced the concept of a 'scale of scrutiny', which he applied to the minimum size of the regions of segregation in the mixture which would cause it to be regarded as imperfectly mixed for specific purposes. The goodness of mixing could be characterized by two factors: the 'scale of segregation' is a measure of the size of the regions of segregation, or 'clumps' of the unmixed components, in an imperfect mixture, while the 'intensity of segregation' is a measure of the departure of the composition from the mean value, averaged over all the points in the mixture. Some proposed experiments were described on the mixing of two differently coloured pastes, where the number of intersections per unit length appearing along a cut section of the mixed material would provide a measure of the scale of segregation. For thick pastes the intensity of segregation will be equal to unity.

Mr. Danckwerts then suggested that dimensional analysis could help considerably in simplifying the mathematical approach to mixing problems. For the mixing of two Newtonian liquids of the same viscosity, the intensity of segregation can be expressed as a function of seven variables, but by use of dimensional analysis this can be reduced to four dimensionless groupings of variables. Some of these groupings represent important properties of the state of the system, such as Reynolds, Froude and Schmidt numbers, while others can be given a physical significance such as 'number of clumps'. These concepts may be of considerable use in 'scaling up' results from models to larger mixers. When mixing liquids of unlike viscosities, many more complications are introduced, and for Bingham solids a dimensionless grouping corresponding to a 'stiffness factor' must be introduced.

Mr. E. H. Jones (British Cotton Industry Research Association) next gave a short paper on "The Preparation of Pastes of Starch and Certain Gums for use in Textile Materials". The property of 'weavability' is imparted to textile threads before weaving, by treating with a sizing solution. The amount of size taken up by the threads as they pass through the solution depends largely on the viscosity of the sizing solution, and it is important to keep this constant. The solution contains some clay as a suspension, some tallow as an emulsion and some inorganic salts as a solution, as well as gelatinized starch and gums as a colloidal suspension. At present, an attempt is being made to develop a machine which will apply a fixed weight of solids to the thread, even if the viscosity of the solution should vary.

In the first paper of the afternoon session, on "The Mixing of Wheaten Flour Doughs", Mr. S. J. Cornford (British Baking Industries Research Association) reviewed the literature on this subject and considered how the mixing characteristics of flour doughs can be used to predict the suitability of a flour for breadmaking. The effect of mixing on flour doughs depends partly on the atmosphere in which the mixing is carried out, as the mechanical effect is modified by air inclusion and oxidation during mixing. Three factors contribute to the resistance encountered during mixing: mechanical resistance, protein swelling and sticking. The peaks in the mixing curve due to these causes do not necessarily coincide, and it is possible for some agents to affect one peak without affecting the others.

A paper by Mr. D. C. Broome (Limmer and Trinidad Lake Asphalt Co.) was read in his absence by Mr. A.E. Howes. Although mixing of thick materials is such an important technical matter to the asphalt industry, there has been little improvement in its mixing machines during the past halfcentury. Some progress is now being made, and a continuous mixer for bituminous road-mixes has been introduced in the United States. In Britain an improved type of 'whirlpool mixer' has recently been developed, and this enables mixing to be carried out in a considerably shorter time than with the older types of mixer. An 'impactor' type of mixer has also been reported from Germany.

A paper from the Road Research Laboratory, West Drayton, submitted by Dr. A. R. Lee, was read in three parts by members of the Laboratory staff. Mr. K. E. Clare gave an account of the problems involved in mixing soil and cement when making special types of road. One of the main difficulties is segregation during in situ mixing due to the greater density of the cement, resulting in a low concentration of cement at the upper surface of the road.

Mr. F. N. Sparkes discussed the problems caused by the fact that engineers tend to specify concrete mixes which are 'leaner' than formerly. Such mixes 
tend to be of much stiffer consistency and result in sticking of the material to the inside of the mixer. 'The efficiency of the tilting, non-tilting and other types of concrete mixer have been investigated recently at the Road Research Laboratory by a sampling procedure, and it has been shown how the mixer can be modified so as greatly to reduce this difficulty.

Dr. R. S. Millard gave an account of the difficulties involved in sampling bituminous mixes used for road construction. A special sectionalized frame has been made for taking samples from a mixer, and it has been shown that quite large variations in bitumen content are to be expected from some types of mixer which are in use at present.

The last paper, by Mr. K. A. Lammiman (Research Council, British Whiting Federation), was on "The Mixing of Linseed Oil Putty". A description was given of the present methods of making putty on a commercial scale, and of the difficulties of measuring oil absorptions for different samples of whiting. The extension before break is an important attribute of the mixed putty, and an extensometer has been constructed to measure this property more accurately than the operative's method of stretching between the hands. Considerable work has been done on the measurement of the density of the material under different conditions of mixing.

The symposium showed that industry is at least aware of the need for attacking mixing problems on a scientific basis. Further progress is to be expected when the methods described by Mr. Danckwerts are applied to the many practical mixing problems described by the other speakers. N. Wooker

\section{RESEARCH STATION OF THE PARSONS AND MARINE ENGINEERING TURBINE RESEARCH AND DEVELOPMENT ASSOCIATION}

\footnotetext{
A $\mathrm{T}$ the open day of the Research Station of the A Parsons and Marine Engineering rurbine Research and Development Association (Pametrada), held on October 5, it was noteworthy that the three and a half years which have elapsed since the Station was last open for viewing have marked a period of considerable expansion as well as the consolidation to be expected after the rapid growth of its first five years. The period also covers the running for rather more than a thousand hours of the $3,500 \mathrm{~s}$.h.p. marine gas-turbine, which was first set in motion in April 1950. The chairman of the Association, Sir Philip Johnson, pointed out in his welcoming address that this installation is a realistic one, small enough, cheap enough and efficient enough to compete economically with other forms of ship propulsion, and with a sufficient life and reliability to bo acceptable for marine service. This is not to say, of course, that there have been none of the teething troubles from which is acquired that valuable experience or 'know how'; but the lines of further development are clear ahead to the extent that the Association is now, in conjunction as usual with its member firms, in a position to produce designs for ships' gas-turbine sets which will be capable of providing the sole propulsion machinery on a satisfactory basis of economy and reliability.
}

The natural attention attracted by this large, impressive and advanced piece of development tended to overshadow the important and interesting exhibits in other parts of the laboratories, almost all of which were on show to the visitor. Work continues on research and development in connexion with steam turbines: there was on show a six-stage impulse machine known as 'Pamela', designed to provide experience with steam at high temperature and high pressure simultaneously, the maximum conditions being $1,100 \mathrm{lb}$. $/$ in. $^{2}$ and $1,100^{\circ} \mathrm{F}$. (about $600^{\circ}$ C.), and there continue to be full-scale trials run on propulsion machinery as a whole, including the turbines and their associated reduction gearing.

A considerable amount of work is going on in connexion with the development of marine reduction gearing and on long-term research into gearing problems. No less than three back-to-back rigs are employed for full-scale work on marine gear units, and in this connexion the Association has developed an ingenious hydraulic device which can be used as a torque loader and torque meter. One of the most interesting exhibits in the gearing section was that which illustrated the effect of helix correction on the life of marine turbine gearing. As is well known, marine turbine pinions have a large length/diameter ratio, and the deflexions on them due to bending, shear and torque are, in sum, considerable. By suitable adjustment of the lead of the two pinion helices with respect to those of the mating wheel, the unit can be made to transmit full load with even loading across the full face-width after taking into account the full deflexions.

Rigs for studying journal bearings, turbine blade vibrations, etc., were also to be seen in the main laboratories. It is particularly noteworthy that the work on bearings has led to the clear establishment of an optimum length/diameter ratio between $1 / 3$ and $2 / 3$. In the small-scale mechanical laboratory were three disk machines of the Amsler, Niemann and Timken types for investigations into gear materials and into problems of gear tooth lubrication, while in the applied science laboratories could be seen further long-term researches into these subjects.

The development work on combustion of fuels for gas turbines and the associated problems of fouling and corrosion were displayed in a series of interesting exhibits in the combustion laboratory. It appears that very considerable progress has been made towards solving the problems of combustion of low-grade fuels in marine gas-turbine installations.

Also as part of the combustion work a considerable number of investigations has been made into problems of oil-fuel spraying. It is particularly interesting to see the relatively large scale of the oil-fuel sprayers developed for the gas-turbine installations as com. pared with the familiar type for compression-ignition engines. The importance in the latter of equal fuel delivered to each cylinder is also paralleled by the need to ensure that multiple combustion chambers give substantially equal outputs per chamber if there are not to be wide variations of inlet temperature around the turbine. Here two developments are continuing in parallel, by improving the sprayers themselves and by the experimental use of a mixing chamber between the flame tubes and the turbine proper. Furthermore, the importance of being able to effect easy replacement of injectors in the com- 